WARE, G. C. (1954). J. gen. Microbiol. 11, 398-400.

\title{
The Effect of Incubation Temperature on the Growth Requirements of Proteus vulgaris and Salmonella typhi
}

\author{
By G. C. WARE \\ Moyne Institute of Preventive Medicine, Trinity College, Dublin
}

SUMMARY: Proteus vulgaris and Salmonella typhi require for growth at temperatures above normal complex nitrogenous substances additional to the media suitable for growth at normal temperature.

It was shown (Ware, 1951) that several strains of Escherichia coli and Aerobacter aerogenes which were able to grow at $37^{\circ}$ in a defined medium were unable to grow in the same medium at higher temperatures. The addition of glutamic acid and nicotinamide to the medium supported growth up to $44^{\circ}$. This paper shows that organisms of other genera become nutritionally more exacting on increase in growth temperature.

\section{METHOD}

The following modification of Gale's (1947) medium devised by Bigger (1950) was used: Glucose, 3.0 g.; $\left(\mathrm{NH}_{4}\right)_{2} \mathrm{HPO}_{4} \cdot 2 \mathrm{H}_{2} \mathrm{O}, 5 \cdot 0$ g.; $\mathrm{NaCl}, 1 \cdot 0$ g.; $\mathrm{FeSO}_{4} .7 \mathrm{H}_{2} \mathrm{O}, 0.3 \mathrm{~g}$.; $\mathrm{MgSO}_{4} \cdot 7 \mathrm{H}_{2} \mathrm{O}, 0.7 \mathrm{~g}$; $\mathrm{KH}_{2} \mathrm{PO}_{4}, 0.5 \mathrm{~g}$; $\mathrm{K}_{2} \mathrm{HPO}_{4}, 5.0$ g.; water to $1000 \mathrm{ml}$; $\mathrm{pH}$ value adjusted to $7 \cdot 4$.

The substances added to the medium were dissolved in distilled water, adjusted to $\mathrm{pH} 7 \cdot 4$, sterilized by boiling and added to the medium to give the final concentration required. The test organisms were grown in the basal medium for $24 \mathrm{hr}$. at $37^{\circ}$ and the inoculum prepared by dilution in buffered saline. Five ml. quantities of the test medium were inoculated with 1 drop of the inoculum from a Pasteur pipette which delivered 22 drops $/ \mathrm{ml}$. An incubator was used for $37^{\circ}$ and below and a water-bath having a stability $\pm 0 \cdot 2^{\circ}$ for higher temperatures. The alternative methods of incubation did not influence the result.

\section{RESULTS}

The effect of temperature on the growth requirements of Proteus vulgaris Our strain of Proteus vulgaris grew well in Lab-lemco broth between $25^{\circ}$ and $44^{\circ}$. In the test medium growth occurred between $25^{\circ}$ and $40^{\circ}$ only when $5 \mathrm{mg}$. nicotinamide $/ 100 \mathrm{ml}$. was added, and was enhanced by the further addition of one of several nitrogenous substances (Table 1). At $41^{\circ}$ addition of any one of a number of these substances was essential for growth; at $42^{\circ}$ only four of these compounds were capable of supporting growth, namely: L-glutamic acid, DL-methionine, L-cystine, thiamine; and at $43^{\circ}$ only L-glutamic acid and DL-methionine; at higher temperatures growth did not occur. The temperature at which growth occurred was limited in some instances by the concentration of the added substance; L-leucine, however, was inhibitory in high concentration. 
Table 1. The effect of various substances on the growth of Proteus vulgaris and of Salmonella typhi in a defined medium at various temperatures

The amounts of growth were read at $48 \mathrm{hr}$. for Proteus vulgaris and at $24 \mathrm{hr}$. for Salmonella typhi.

\begin{tabular}{|c|c|c|c|c|c|c|c|c|c|}
\hline \multirow[t]{3}{*}{ - } & \multicolumn{7}{|c|}{ P. vulgaris } & \multicolumn{2}{|c|}{ S. typhi } \\
\hline & \multicolumn{9}{|c|}{ Temperature of growth } \\
\hline & $40^{\circ}$ & \multicolumn{2}{|c|}{$41^{\circ}$} & \multicolumn{2}{|c|}{$42^{\circ}$} & \multicolumn{2}{|c|}{$43^{\circ}$} & \multicolumn{2}{|c|}{$40^{\circ}$} \\
\hline & \multicolumn{9}{|c|}{ Concentration $(\mathrm{mg} . / 100 \mathrm{ml})}$. \\
\hline defined medium & $0 \cdot 01$ & $10-100$ & $1 \cdot 0$ & $10-100$ & $1 \cdot 0$ & $10-100$ & $1 \cdot 0$ & $10-100$ & $1 \cdot 0$ \\
\hline L-Alanine & $\mathbf{x}$ & 0 & $\mathbf{0}$ & 0 & $\mathbf{0}$ & 0 & $\mathbf{0}$ & o & 0 \\
\hline L-Arginine & $\mathbf{x}$ & $\mathbf{x}$ & $\mathbf{x}$ & $\mathbf{0}$ & $\mathbf{0}$ & $\mathbf{0}$ & $\mathbf{0}$ & $\mathbf{x}$ & $\mathbf{X}$ \\
\hline L-Asparagine & $\mathbf{x}$ & $\mathbf{x}$ & $\mathbf{x}$ & 0 & $\mathbf{0}$ & 0 & 0 & $\mathbf{0}$ & 0 \\
\hline L-Aspartic acid & sl. & $\mathbf{x}$ & 0 & $\mathbf{0}$ & $\mathbf{0}$ & $\mathbf{0}$ & $\mathbf{0}$ & $\mathbf{0}$ & 0 \\
\hline L-Cystine & $\mathbf{x}$ & $\mathbf{x}$ & $\mathbf{x}$ & $\mathbf{x}$ & $\mathbf{x}$ & $\mathbf{0}$ & 0 & $\mathbf{0}$ & 0 \\
\hline L-Glutamic acid & $\mathbf{X}$ & $\mathbf{X}$ & $\mathbf{x}$ & $\mathbf{x}$ & $\mathbf{x}$ & $\mathbf{x}$ & $\mathbf{0}$ & $\mathbf{x}$ & $\mathbf{x}$ \\
\hline Glycine & sl. & o & 0 & 0 & 0 & 0 & 0 & 0 & $\mathbf{0}$ \\
\hline L-Histidine & $\mathbf{x}$ & $\mathbf{x}$ & $\mathbf{x}$ & $\mathbf{0}$ & $\mathbf{0}$ & 0 & 0 & 0 & 0 \\
\hline L-Isoleucine & $\mathbf{x}$ & $\mathbf{x}$ & $\mathbf{x}$ & $\mathbf{0}$ & 0 & $\mathbf{0}$ & $\mathbf{0}$ & $\mathbf{0}$ & 0 \\
\hline L-Leucine & $\mathbf{x}$ & 0 & 0 & $\mathbf{0}$ & 0 & 0 & $\mathbf{0}$ & $\mathbf{0}$ & $\mathbf{0}$ \\
\hline L-Lysine & $\mathbf{X}$ & $\mathbf{x}$ & $\mathbf{x}$ & 0 & 0 & 0 & $\mathbf{0}$ & $\mathbf{x}$ & $\mathbf{x}$ \\
\hline DL-Methionine & $\mathbf{x}$ & $\mathbf{x}$ & $\mathbf{x}$ & $\mathbf{x}$ & $\mathbf{x}$ & $\mathbf{x}$ & $\mathbf{0}$ & 0 & 0 \\
\hline Nicotinamide & - & - & - & - & - & - & - & 0 & 0 \\
\hline Thiamine & $\mathbf{x}$ & $\mathbf{x}$ & $\mathbf{x}$ & $\mathbf{x}$ & $\mathbf{0}$ & 0 & $\mathbf{0}$ & $\mathbf{x}$ & $\mathbf{0}$ \\
\hline DL-Tryptophan & $\mathbf{x}$ & $\mathbf{x}$ & $\mathbf{x}$ & 0 & $\mathbf{0}$ & 0 & $\mathbf{0}$ & $\mathbf{0}$ & 0 \\
\hline L-Valine & $\mathbf{x}$ & $\mathbf{0}$ & 0 & 0 & 0 & $\mathbf{0}$ & $\mathbf{0}$ & $\mathbf{0}$ & 0 \\
\hline \multicolumn{10}{|l|}{ Controls } \\
\hline $\begin{array}{l}\text { Defined medium + } \\
5 \mathrm{mg} . / 100 \mathrm{ml} . \\
\text { nicotinamide }\end{array}$ & sl. & \multicolumn{2}{|l|}{$\mathbf{0}$} & \multicolumn{2}{|c|}{$\mathbf{0}$} & \multicolumn{2}{|c|}{$\mathbf{0}$} & \multicolumn{2}{|c|}{0} \\
\hline Defined medium & 0 & \multirow{2}{*}{\multicolumn{2}{|c|}{$\mathbf{0}$}} & \multirow{2}{*}{\multicolumn{2}{|c|}{$\begin{array}{l}\mathbf{0} \\
\mathbf{x}\end{array}$}} & \multirow{2}{*}{\multicolumn{2}{|c|}{$\mathbf{0}$}} & \multicolumn{2}{|c|}{0} \\
\hline Lemco broth & $\mathbf{x}$ & & & & & & & \multicolumn{2}{|c|}{$\mathbf{X}$} \\
\hline
\end{tabular}

$$
0=\text { no turbidity } ; X=\text { turbidity } ; \text { sl. = slight turbidity. }
$$

The effect of temperature on the growth requirements of Salmonella typhi

The growth of our strain of Salmonella typhi in $24 \mathrm{hr}$. at $37^{\circ}$ in the test medium was enhanced by the addition of any one of a number of nitrogenous substances in concentrations of from $1 \mathrm{mg}$. $/ \mathrm{ml}$. to $1 \mathrm{mg} . / 100 \mathrm{ml}$. The only substance which had an adverse effect on growth was nicotinamide. There was no growth after incubation at $40^{\circ}$ for $24 \mathrm{hr}$. unless one of the following substances was added: L-glutamic acid, thiamine, L-lysine, L-arginine. At $43^{\circ}$ no single addition tested was able to support growth, but L-glutamic acid + $\mathrm{L}$-arginine with either thiamine or L-lysine showed growth in $\mathbf{2 4} \mathbf{~ h r}$.; without L-arginine growth was delayed for $48 \mathrm{hr}$. The addition of DL-methionine either to L-glutamic acid + L-lysine or to L-glutamic acid + thiamine inhibited growth, but there was no inhibition when DL-methionine was added to L-glutamic acid + thiamine + L-lysine; thiamine or L-lysine could, in this combination, be 
replaced by L-arginine which also overcame the inhibitory effect of DL-methionine. L-Glutamic acid was always essential for growth. Although active at $10 \mathrm{mg}$. $100 \mathrm{ml}$. the optimum concentration of each substance was approximately $200 \mathrm{mg} . / 100 \mathrm{ml}$.

\section{DISCUSSION}

Hills \& Spurr (1952) and Ware (1951) suggested that increase in incubation temperature caused changes in certain nutritional enzyme systems; it appears that enzymes responsible for L-glutamic acid formation may be among the first to be affected by increased temperature.

I wish to thank the Medical Research Council of Ireland for a grant in connexion with this work, and Prof. F. S. Stewart, for advice and facilities.

\section{REFERENCES}

BigGER, J. W. (1950). Synergism and antagonism as displayed by certain antibacterial substances. Lancet, ii, 46.

GaLE, E. F. (1947). The Chemical Activities of Bacteria. London: University 'Tutorial Press Ltd.

Hills, G. M. \& Spurr, E. D. (1952). The effect of temperature on the nutritional requirements of Pasteurella pestis. J. gen. Microbiol. 6, 64.

WARE, G. C. (1951). Nutritional requirements of Bacterium coli at $44^{\circ}$. J. gen. Microbiol. 5, 880.

(Received 15 May 1954) 